Sheffield

Hallam

University
Centre for

Regional Economic

and Social Research

\title{
Assessment of the need for furniture provision for new NIHE tenants
}

\section{March 2016}




\section{Assessment of the need for furniture provision for new NIHE tenants}

Authors:

Aimee Ambrose

Elaine Batty

Will Eadson

Paul Hickman

George Quinn

March 2016 


\section{Contents}

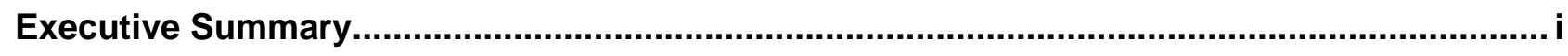

1. Introduction

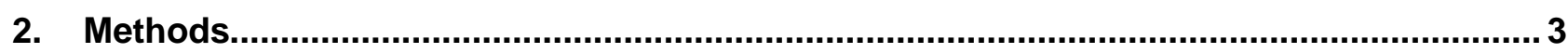

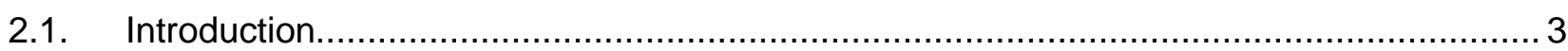

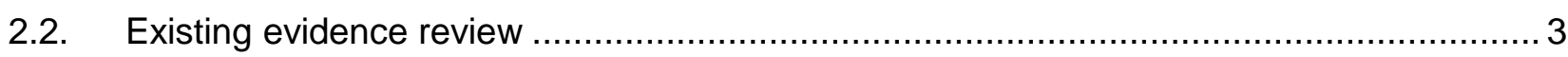

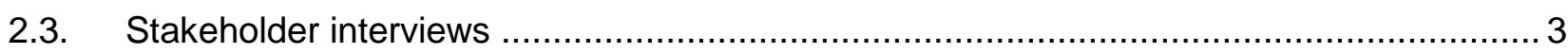

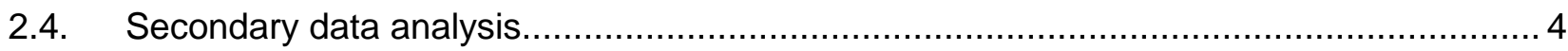

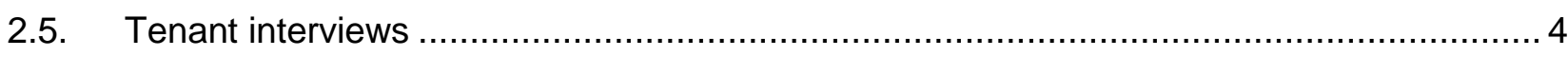

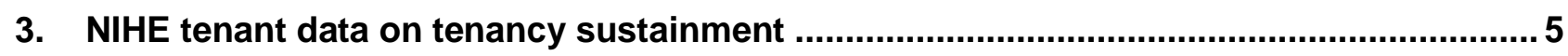

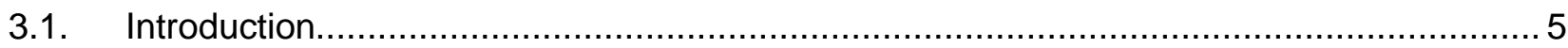

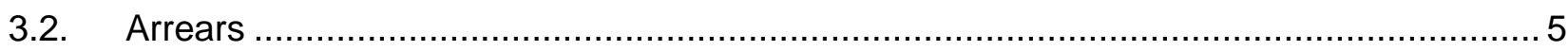

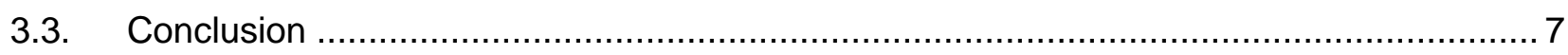

4. Existing evidence on the benefits of furniture provision................................................. 8

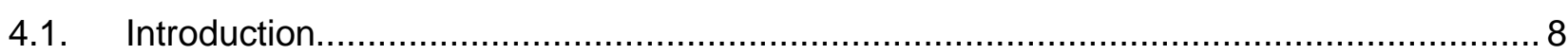

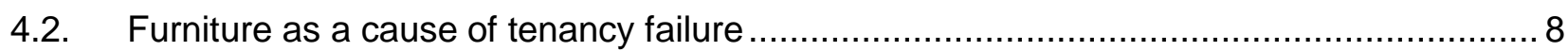

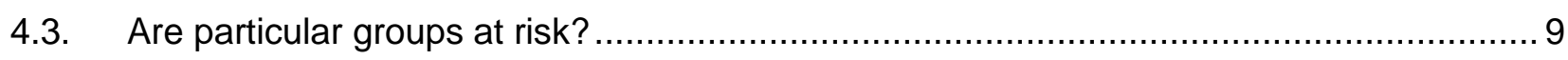

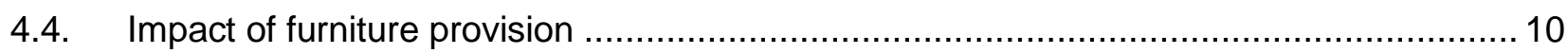

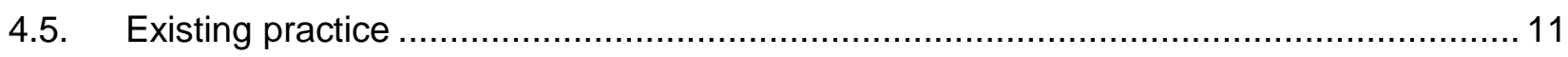

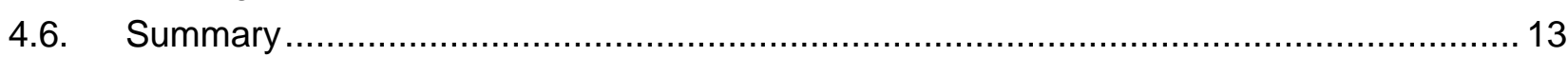

5. Stakeholder perceptions of the value of furniture provision...........................................14

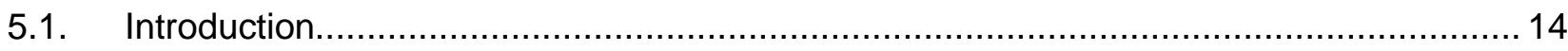

5.2. Impact of inadequate furniture provision tenancy sustainment................................. 14

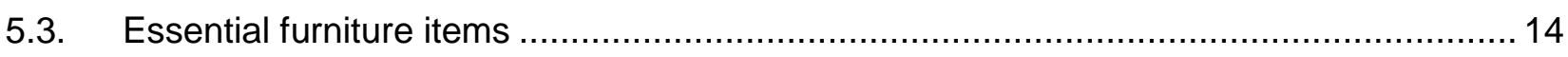

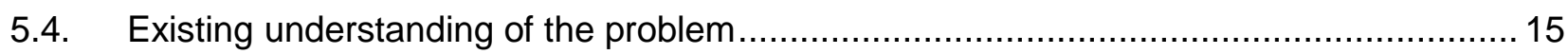

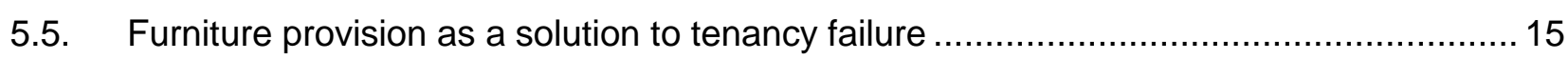

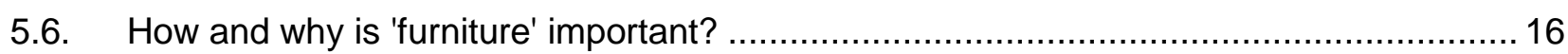

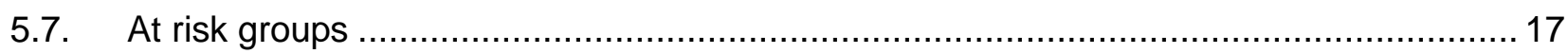

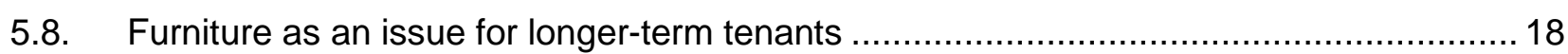

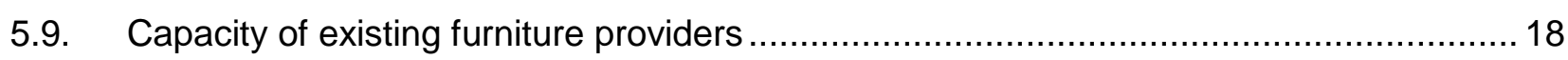

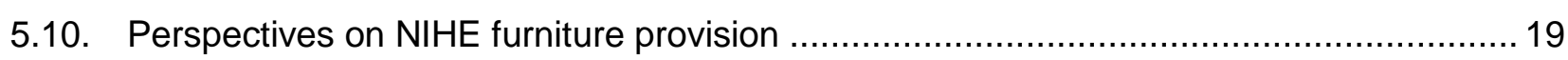




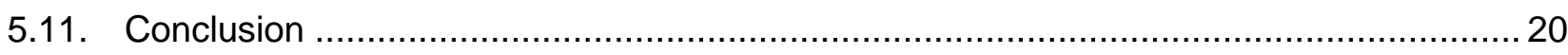

6. Tenant perceptions on the need for furniture provision ............................................ 21

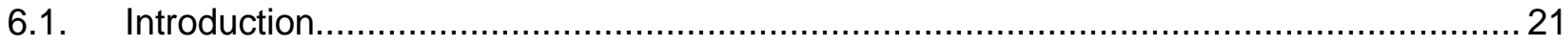

6.2. The importance of furniture in a new home........................................................... 21

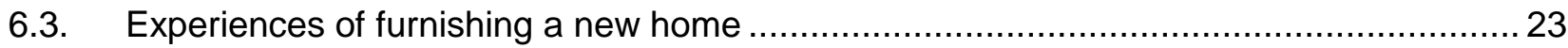

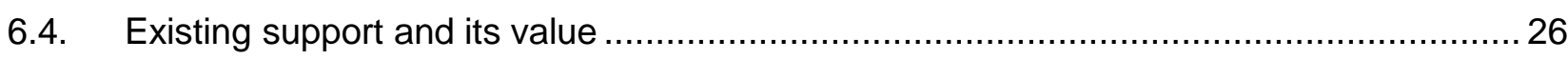

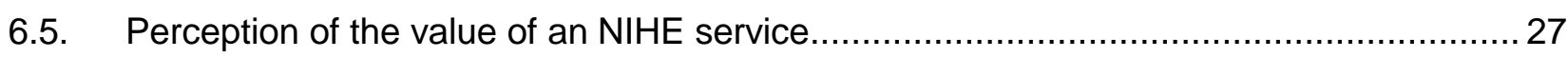

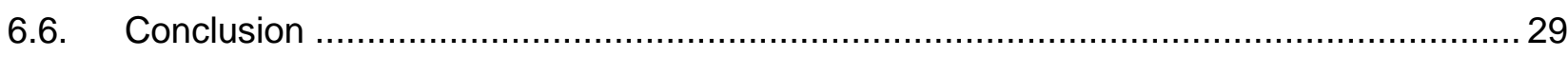

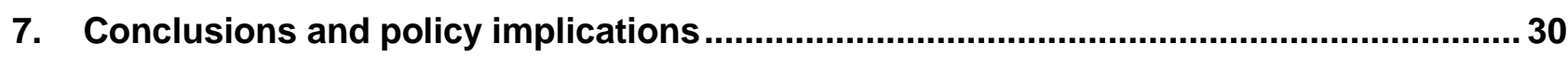

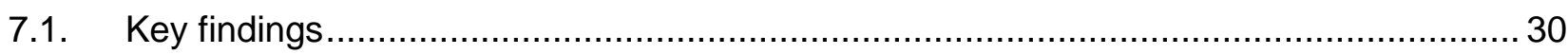

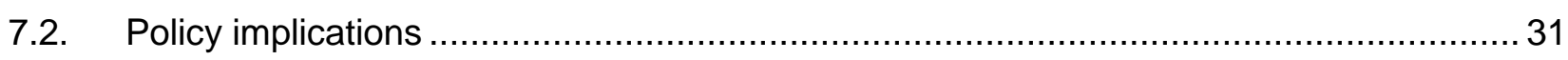

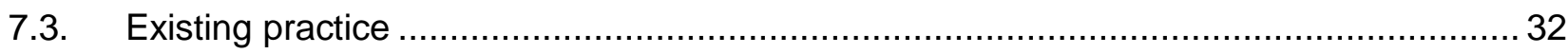

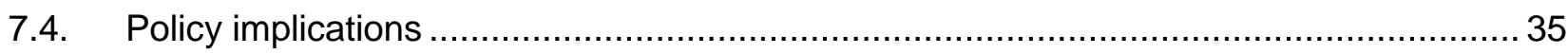

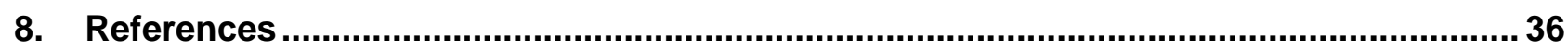




\section{Executive Summary}

The Centre for Regional Economic and Social Research (CRESR) at Sheffield Hallam University and the Council for the Homeless Northern Ireland ( $\mathrm{CHNI}$ ) were commissioned by the Northern Ireland Housing Executive (NIHE) to assess the need for furniture provision for its new tenants. This report is the final output from the study. It follows an initial scoping report based on an evidence review and stakeholder interviews, and a report outlining headline findings from interviews with current, former and prospective NIHE tenants.

The research had four key objectives, as follows:

- A review of existing research, policy and practice in Great Britain and Northern Ireland.

- Examining existing policies, procedures and practices used by NIHE when a new tenant indicates the need for assistance with essential household furniture.

- Assessing the extent of and, if possible, reasons for failed tenancies (lasting <12 months) within the last two years.

- Estimating other associated housing-related benefits of furniture provision to tenants and their families.

The research comprised the following activities:

- A review of the academic literature relating to the impact of furniture provision on tenancy sustainability.

- A review of current and past practice by social housing landlords in relation to furniture provision.

- An analysis of secondary data held by NIHE relating to the need for furniture provision for new tenants.

- $\quad$ Eight in-depth interviews with policy and practice experts within the field of furniture provision and tenancy sustainability.

- 34 in-depth interviews with future, current and former NIHE tenants.

The findings set out below are exploratory and indicative, as befits the research brief. Further work will be required by NIHE to flesh out specifically how a furniture service might operate and particularly the technical details of its operation. However there are number of key findings that can be drawn from the research.

Furniture is important to tenants' wellbeing and extends beyond seating and beds. A lack of furniture undermines the comfort and residential experience of tenants; has adverse psychological impacts; and can reduce the likelihood that a property will become a 'home' for tenants. Essential items include chairs and beds, but also white goods such as fridges and cooking facilities. Existing $\mathrm{NIHE}$ tenants also talked about curtains and flooring as critical furnishings.

Difficulties furnishing a tenancy can be a cause of tenancy failure. Some groups are particularly at risk of tenancy failure, with furniture a contributing factor. This includes homeless 
people, young people, care leavers and people with physical and/or learning difficulties. However, furnishing a tenancy is part of a bundle of on-going practices that make a place 'feel like home'. As such, furniture provision is not a panacea for solving tenancy failure.

Difficulty furnishing tenancies is an issue in NIHE tenancies. Stakeholders estimated that as many as 50 per cent of new tenants have difficulty acquiring furniture, and tenants in a range of situations detailed the different challenges they had faced acquiring and paying for furniture. Tenants frequently took on (additional) debt to pay for furnishings.

Furniture provision services can reduce tenancy failure. For example, in a study of tenancy sustainment in Glasgow, Pawson et al (2006) found that tenancy termination was 15 percentage points higher among unfurnished compared to furnished tenancies. However, depending on how support is provided, there can be some limitations to furniture provision - for example, a lack of choice for tenants could limit its effectiveness - and complexities around housing benefit could in some situations lead to financial difficulties for tenants receiving furniture support. In particular, the potential for a 'poverty trap' potentially created by the cost of service charges when a tenant moves off housing benefit can be problematic.

Potential, existing and former NIHE tenants were positive about furniture provision. Tenants in a range of different circumstances would value the option of NIHE-provided furniture. Many tenants would be willing to pay an additional service charge for the service, especially if it were covered by housing benefit. However, respondents said that they would need to know about how such a scheme would work in practice, for instance: the degree of choice for tenants; clarity regarding ownership of furniture; and concerns about costs if a tenant moves off housing benefit.

Existing furniture provision schemes in England, Scotland and Wales show that furniture provision services delivery by RSLs are viable. The Your Homes Newcastle (YHN) Furniture Service, for example, provides furniture to 6,000 YHN tenancies. Tenants pay for the service through a service charge which is eligible to be covered by housing benefit, as long as the payments do not end with the tenant owning the furniture (this will continue under Universal Credit). YHN include the risk of loss or damage of furniture within their pricing structure, although this risk has been found to be low over time. The introduction of Universal Credit creates additional risks, however, as tenants will be responsible for paying rent and service charges from their combined UC payment, rather than payments going direct to landlords. 


\section{Introduction}

The Centre for Regional Economic and Social Research (CRESR) at Sheffield Hallam University and the Council for the Homeless Northern Ireland (CHNI) were commissioned by the Northern Ireland Housing Executive (NIHE) to assess the need for furniture provision for its new tenants. This report is the final output from the study. It follows an initial scoping report based on an evidence review and stakeholder interviews, and a report outlining headline findings from interviews with current, former and prospective NIHE tenants.

The research has four key objectives, as follows:

- A review of existing research, policy and practice in Great Britain and Northern Ireland.

- Examining existing policies, procedures and practices used by NIHE when a new tenant indicates the need for assistance with essential household furniture.

- $\quad$ Assessing the extent of and if possible reasons for failed tenancies (lasting $<12$ months) within the last two years.

- Estimating other associated housing-related benefits of furniture provision to tenants and their families.

The findings set out below are exploratory and indicative, as befits the research brief. Further work will be required by NIHE to flesh out specifically how a furniture service might operate and particularly the technical details of its operation. NIHE will likely need to take specialist legal advice on these issues.

Data on tenants' perceptions are qualitative, covering a relatively small number of tenants. This approach is very useful for developing an in-depth understanding of the range of tenant experiences, and for understanding the context in which different forms of support might be more or less valued. However, the findings should not be taken as a definitive reading on the level of demand or take-up for a furniture provision service: a more extensive quantitative exercise would be required to better understand this.

The remainder of this report is structured as follows. Section 2 outlines in more detail the methods employed during the research project, including sampling methods and our approach to contacting research participants. Section 3 then takes a look at NIHE tenancy data, exploring whether there are particular groups of tenants who might be more at risk of tenancy failure, which might indicate an increased need for furniture support. Section 4 focuses on existing evidence from academic and policy 
literature on the potential benefits of furniture provision, which is followed in Section 5 by discussion of findings from interviews with key stakeholders about their experiences and perceptions of furniture provision in social housing. Section 6 moves on to explore findings from interviews with existing, former and prospective tenants, including their experiences of setting up home, and the extent to which they would value a furniture provision service. Finally, Section 7 reviews the key findings from the report and outlines the policy implications for NIHE. 


\section{Methods}

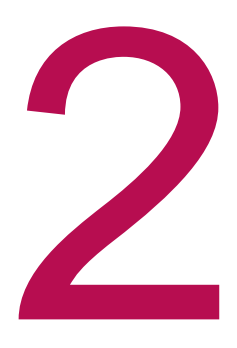

\subsection{Introduction}

This section outlines the methods for the research. The research comprises the following elements:

- A review of the academic literature relating to the impact of furniture provision on tenancy sustainability.

- A review of current and past practice by social housing landlords in relation to furniture provision.

- An analysis of secondary data held by NIHE relating to the need for furniture provision for new tenants.

- In-depth interviews with policy and practice experts within the field of furniture provision and tenancy sustainability.

- In-depth interviews with future, current and former NIHE tenants.

\subsection{Existing evidence review}

The scoping review explored existing academic and grey literature on the impact of furniture provision on tenancy sustainability; a review of current and past practice by social landlords; and interviews with stakeholders in Northern Ireland.

Internet searches were carried out using academic databases, Google and Google Scholar. 21 academic and policy documents were reviewed. This was then complemented with a review of existing furniture provision practice across England, Scotland and Wales to draw out an understanding of the practical possibilities for furniture provision. The review included desk-based searches as well as interviews with representatives of three housing providers who had longstanding experience of providing furniture to tenants.

\subsection{Stakeholder interviews}

Eight in-depth interviews with policy and practice experts within the field of tenancy sustainability and furniture provision were conducted with stakeholders in Northern Ireland. The following organisations were represented within the interview sample: NIHE; the Chartered Institute of Housing; the Housing Rights Service; and a leading Northern Ireland-based housing association. 


\subsection{Secondary data analysis}

In order to better understand the population groups most at risk of tenancy failure, analysis was conducted of NIHE data on existing and former tenants. This involved analysing key variables relating to tenancy failure - arrears and early tenancy termination - in relation to different demographic variables. The records of 14,095 tenants were analysed.

\subsection{Tenant interviews}

The research also included interviews with existing, prospective and former NIHE tenants. NIHE provided a dataset of people matching each of these areas and a sample was constructed, weighted towards those aged 18-23 and - in the cases of existing and former tenants - only people whose tenancies had lasted for less than two years were included. The sample focused on three areas of Northern Ireland: East Belfast, Derry / Londonderry-Waterside and Newry.

Arranging and completing interviews was extremely challenging. In total over 400 telephone calls were made to tenants. Around 40 per cent of the contacts were 'dead lines' and so have been un-contactable. All others were called at least twice, with answer machine messages left. In addition follow-up letters were sent to 130 tenants asking them to contact a member of the research team if they were willing to take part in the research. In order to top up the sample we also contacted VCS support organisations in Newry, Belfast and Derry/ Londonderry to help us contact prospective and existing tenants who received some support with their furniture.

A total of 34 interviews were completed. A further 18 interviews were arranged but the participant was unable for whatever reason to make the appointment. Given the difficulties in obtaining interviews the research team was not able to adhere strictly to the sampling frame. The final breakdown of respondents was as follows:

- 13 female and 21 male respondents

- 25 respondents from Belfast (including 18 from East Belfast), five from Derry / Londonderry and four from Newry

- 24 existing tenants, nine tenants on the waiting list, and one former tenant

- Six respondents in some form of paid employment, and 26 who were not working (two respondents did not provide their employment status). 


\section{NIHE tenant data on tenancy sustainment}

\subsection{Introduction}

In order to better understand the groups at most risk of tenancy failure, an analysis was conducted of NIHE data on arrears. The results are briefly outlined in this section. The research team also intended to analyse early tenancy termination data (tenancies lasting less than one year). However, this dataset was found to be too small to conduct any meaningful analysis. The dataset as a whole had a large amount of missing data. As such the findings below should be treated with a high degree of caution.

\subsection{Arrears}

Arrears data were analysed by age, whether or not a tenant was a Full Duty Applicant (i.e. were homeless or threatened with homelessness prior to taking up a tenancy), gender, and by marital status. Overall, 42 per cent of tenants were recorded as having been in arrears for seven weeks or more over the preceding two years. However, the remaining 58 per cent were recorded as 'NULL' in the dataset: it is not clear if all of these tenancies are not in arrears or whether some of these were missing data. As such it is possible that arrears levels are higher than recorded here.

Figure 1 below shows arrears levels by age. It shows that, overall, those aged 26-39 were most likely to have spent seven weeks or more in arrears with their rent over the last two years. This group was also most likely to have been in arrears for more than 52 weeks in the last two years. However, those aged 16-25 recorded the highest levels of arrears under 52 weeks. These findings mirror findings from research on tenancy failure conducted by CRESR for a group of housing associations in England. ${ }^{1}$ This might be explained by the fact that younger tenants are - in general - likely to have been in their tenancy for a shorter period than older tenants. 26 per cent of tenants aged 25 or under had been in their tenancy for less than 19 weeks, compared to just 12 per cent of $26-39$ year olds.

\footnotetext{
${ }^{1}$ Ambrose, A., Eadson, W., Hickman, P. and McCarthy, L. (2015) Tenancy sustainment amongst those aged under 35. Sheffield: CRESR, Sheffield Hallam University.
} 
Figure 1: Weeks in rent arrears in the last two years by age group

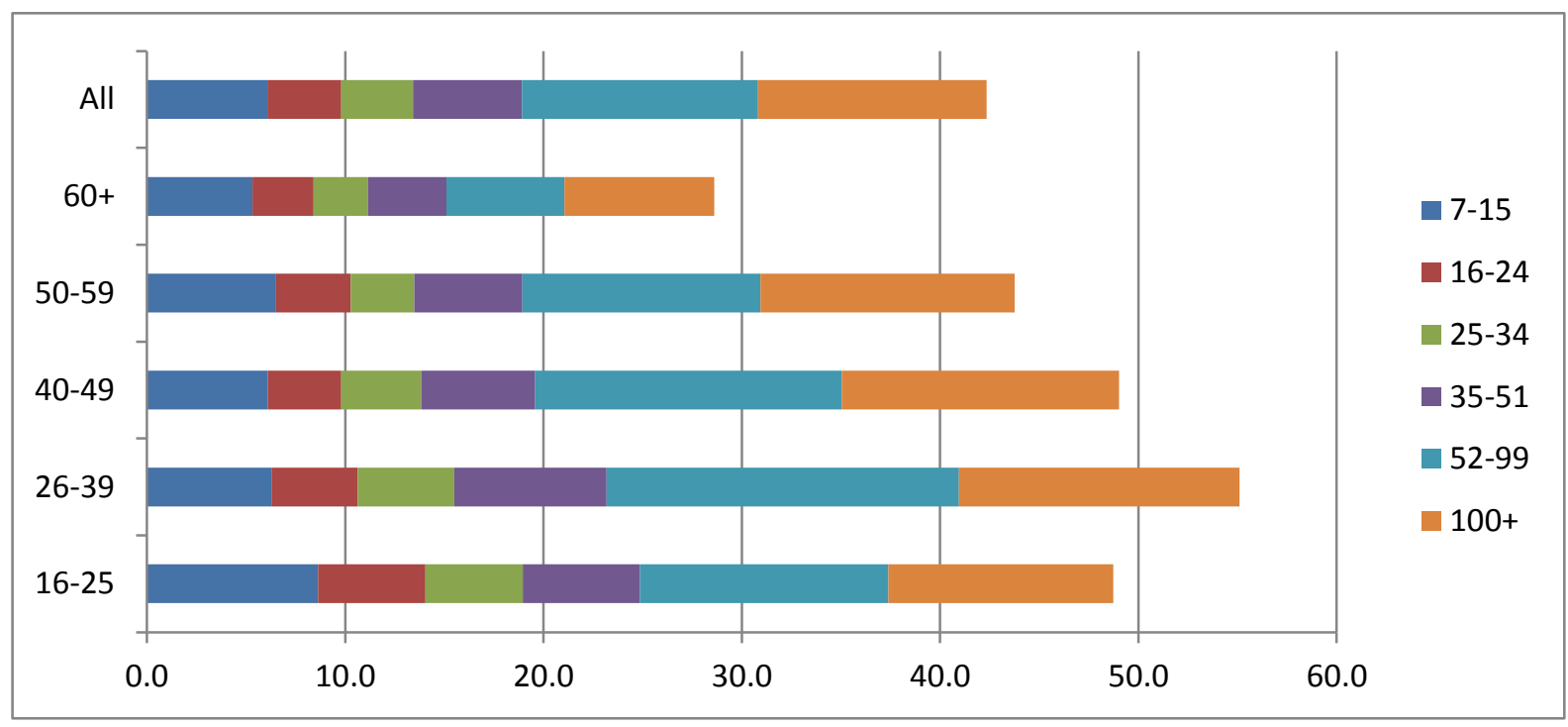

On the whole there was little difference in arrears between different genders. However, female tenants were slightly more likely to have been in arrears for 100 weeks or more within the last two years (13 per cent against 10 per cent of male tenants). There was some difference in numbers of weeks in arrears when looking at whether a tenant had been homeless prior to entering an NIHE tenancy. Figure 2 below shows that tenants who were not Full Duty Applicants were more likely to have been in more than seven weeks' arrears in the last two years. This finding is contrary to evidence that suggests tenants from a homeless background are more likely to struggle with their tenancy. Again, however, these tenants are more likely to be newer tenants, and it might be that they also receive a greater level of support than other tenants to help them overcome the challenges they face.

Figure 2: Number of weeks in arrears over the last two years by FDA status

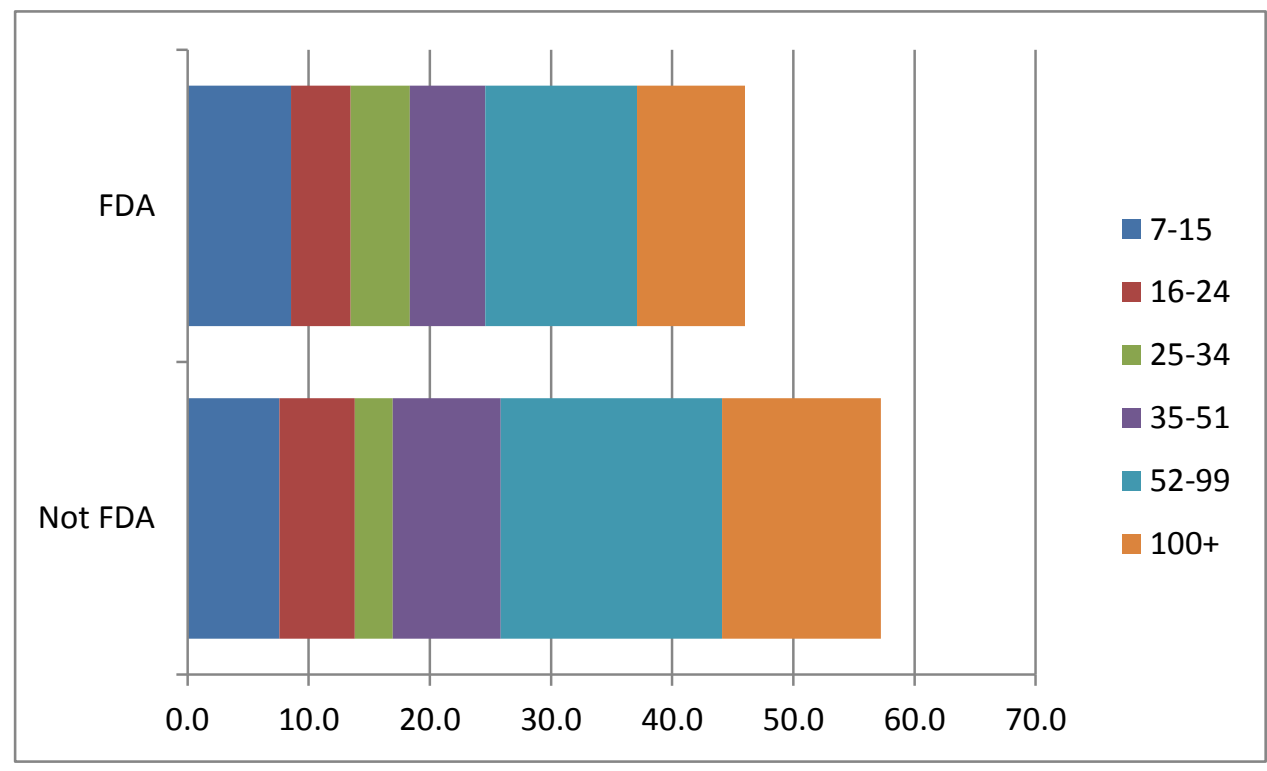

Figure 3 shows data for marital status by number of weeks in arrears over the last two years. It shows that people designated as 'separated' were most likely to have spent more than seven weeks in arrears over the last two years, while those designated as 'cohabiting' we most likely to have been in arrears for 52 weeks or 
more over the last two years. 'Single' tenants were less at risk than any group other than 'widowed'.

Figure 3: number of weeks in arrears over the last two years by marital status

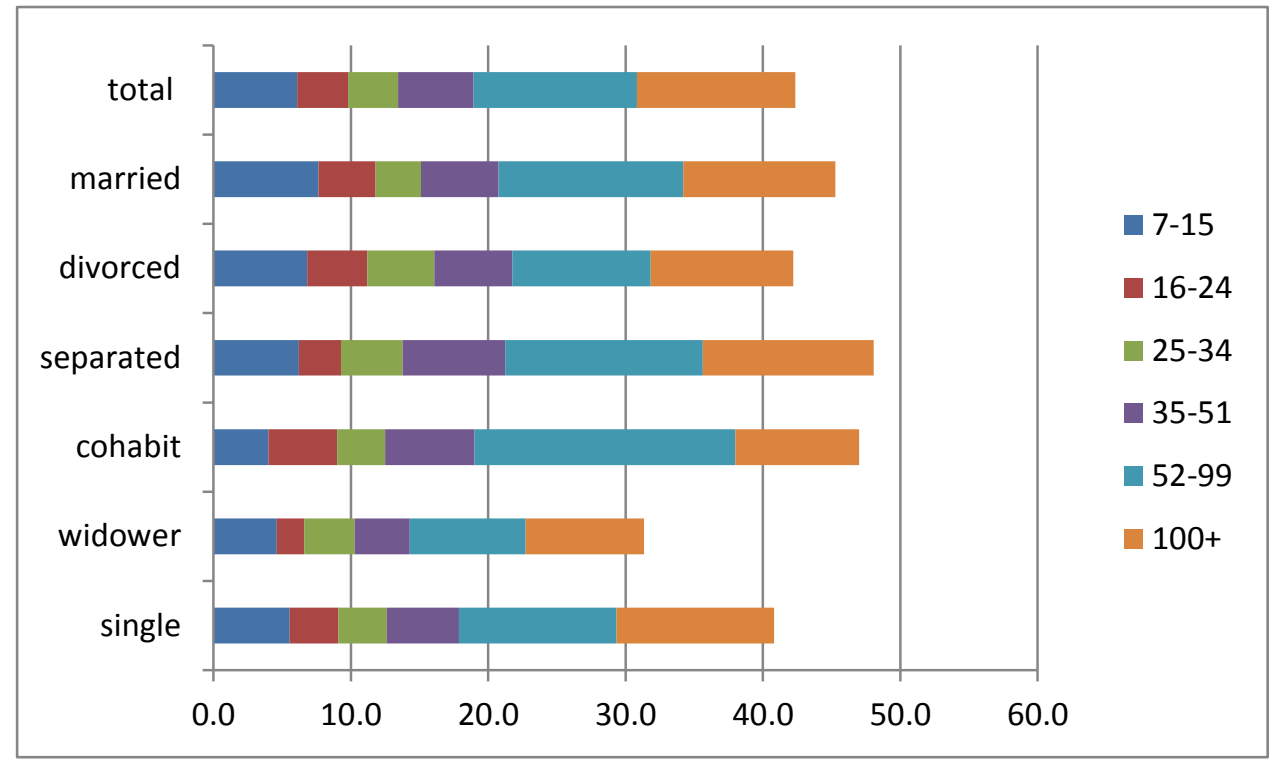

\subsection{Conclusion}

This section gave a brief overview of analysis of NIHE tenancy data. It showed that, on the whole, those aged under 40 were more likely to have been in arrears in the preceding two years than other age groups, with 26-39 year-olds most likely to have been in arrears for more than 52 of the preceding 104 weeks. Homeless people were not more likely to have been in extensive arrears, nor were single people. Combined these findings are perhaps counter-intuitive. As noted the dataset was very 'patchy' in terms of completion of different fields, so it might be that this hides the true picture of tenancy behaviour. But the findings do point to the fact that all groups experience difficulties with their tenancies, which is important to bear in mind when considering offering support such as furniture provision. 


\section{Existing evidence on the benefits of furniture provision}

\subsection{Introduction}

To foreground interviews with stakeholders and tenants, a review of the existing evidence base was conducted. This included a review of academic, evaluation and policy literature, which sought to answer three key questions:

- To what extent is furniture an important factor in tenancy failure and/or sustainment?

- Are particular groups at risk of facing difficulties acquiring furniture and/or of tenancy failure as a result of difficulties acquiring furniture?

- What impact does furniture provision have on tenancy sustainment?

21 academic and policy documents were reviewed. This was then complemented with a review of existing furniture provision practice across England, Scotland and Wales to draw out an understanding of the practical possibilities for furniture provision.

\subsection{Furniture as a cause of tenancy failure}

A key point to note from the literature is that furniture provision is not a panacea to solve tenancy sustainment problems. Rather, acquiring furniture is part of a bundle of on-going practices that make a place 'feel like home': "it is not only the building of a home that is important but continuous practical activities such as paying the bills and buying food which 'makes it feel like home'" (Stewart, 2013, p123). In this vein Stewart outlines four important practices for tenancy sustainment:

- 'building a home': furnishing, décor and so on

- 'practical mastery': ability to practically manage the home (e.g. cooking, cleaning, dealing with the practicalities of paying bills)

- budgeting, which intertwines with securing and maintaining an income

- 'techniques with others': managing relationships with family, friends, landlords and other support services.

In a longitudinal survey of 400 rehoused single homeless people in the UK, Warmes et al (2013) found that difficulties obtaining furniture or household equipment did not have a significant relationship with tenancy termination over a three year period. They argue that "such shortcomings can be rectified over time, unlike neighbourhood problems, poor transport links and restricted space that are out of tenants' control". In concordance with Tsai et al (2012), they felt that a critical factor was lack of control. 
The issue of control chimes with other sources, including Stewart (2013) and might suggest that the lack of furniture is not in itself a key determinant of tenant sustainment: rather it is the extent to which tenants feel they could determine their furnishings - either qualitatively or quantitatively - over time. ${ }^{2}$

Yet - despite this evidence - it is clear that furnishing a home can pose significant challenges for some tenants and can be a primary factor in early tenancy termination. Difficulties acquiring furniture might also be a factor working alongside other challenges faced by tenants: for instance a combination of the four practices outlined above, or physical or mental health problems.

In an evaluation of tenancy sustainment in Glasgow, Pawson et al (2006) found that, although experiencing anti-social behaviour or difficulties with neighbours was the most common reason for giving up a tenancy, inability to secure adequate furniture and equipment featured highly. Other reasons given included:

- $\quad$ being allocated a home in an unwanted area

- dissatisfaction with property condition

- debt problems resulting from poverty and an inability to maximise income and/or manage money

- $\quad$ social isolation.

Pawson et al (ibid. p75) conclude that "it is clear... that obtaining basic furniture and 'white goods' can be a major problem for some newly rehoused applicants, especially those unable to rely on the charity of friends and/or family". As the Homelessness Task Force (2002) put it, "for many homeless people, the offer of an unfurnished tenancy is not enough because they lack the means to provide basic furniture. In these circumstances, the tenancy is unlikely to be viable or sustainable".

\subsection{Are particular groups at risk?}

The literature suggests that some groups are particularly at risk of experiencing difficulty sustaining a tenancy (homeless people, young people, care leavers, and people with physical and/or learning difficulties). In particular, for many younger tenants, or those that were previously in supported accommodation, new-found independence on moving into a tenancy was initially offset by feelings of insecurity as support was removed or reduced: having to deal with acquiring furniture, alongside on-going tasks of managing a tenancy such as budgeting, cooking, cleaning, paying bills and so on added to this sense of isolation and insecurity (Stewart, 2013).

The more 'at risk' groups of people are those that for various reasons might not have had the opportunity to develop (or have lost over time) the capabilities required to live independently, for instance people who have not previously held a tenancy of their own (Pawson and Munroe, 2010). They are also less likely than other groups to possess the financial resources to acquire furnishings, as well as lacking the social networks (or 'capital') to acquire furnishing through friends and families (Pawson et al, 2006; Stewart, 2013).

\footnotetext{
${ }^{2}$ It should be noted that this study did not include any homeless people with long-term mental or physical health problems or tenants with a history of substance misuse, so does not capture the full range of people who might potentially require support with furnishings.
} 
Nonetheless, people in a wide range of circumstances might have difficulties acquiring furniture: for instance as a result of family breakdown or bankruptcy (JRF, 1997). It is worth noting that Pawson et al (2006) found that in Glasgow early tenancy termination was as likely among people rehoused through the waiting list as those who were formerly homeless.

\subsection{Impact of furniture provision}

Given that difficulties acquiring furniture can be a cause of tenancy failure it would seem to logically follow that furniture provision can be important in sustaining tenancies. This is backed-up by the evidence. Rooney (1998) found that 25 per cent of interviewed tenants $(n=83)$ felt that they would have lost their tenancy without support with furnishing their home, and research by Pawson et al (2006) found that tenancy termination was 15 percentage points higher among unfurnished compared to furnished tenancies ( 25 per cent versus 10 per cent termination rate in 2003).

For a sense of the broader benefits of furniture provision, Richards (2007) conducted a social return on investment (SROI) assessment of furniture provision in Liverpool. This found returns of $£ 2.11$ for every $£ 1$ invested. Benefits included:

- increased disposable income

- $\quad$ creation of a viable home

- $\quad$ reduced rent arrears and void costs for registered social landlords (RSLs)

- improved confidence among tenants

- $\quad$ increased time for alternative activities (e.g. seek employment)

- guaranteed revenue to RSLs through repayments

- improved stakeholder relations

- improvements to sustainability of tenancies.

Furniture projects can also provide jobs and training places, and in 2011 furniture reuse projects in Scotland diverted 13,600 tonnes from landfill (CRNS, 2012).

There are both limits and limitations to furniture provision, however. Importantly only a relatively small proportion of tenants are in critical need of support: for instance, Timmins and Gulliver (2015) estimate that between five and seven per cent of tenants require support with acquiring furniture. The literature also points to a number of other limitations, as summarised by Rooney (1997):

- Lack of choice over furniture received: Stewart (2013) also found that ownership, choice and control come through as important for tenants. This is bound up with a feeling that 'a home' as opposed to a dwelling was something that was built by the tenant: it was an outcome of work they put in.

- Housing benefit regulations mean that ownership of goods must remain with the RSL: this can cause difficulties in transferring to a new tenancy elsewhere.

- There can be uncertainty among tenants regarding responsibility for maintenance or what would happen if they wanted to end the furniture element of a tenancy, but remain in the same accommodation.

- Cost of service charge: while generally covered by housing benefit (HB), this can cause problems if the tenant moves off HB and into paid employment. 
Of the limitations outlined above the most problematic is the 'poverty trap' potentially created by the cost of service charges when a tenant moves off housing benefit. The literature reviewed here does not pose any solutions to this.

\section{5. $\quad$ Existing practice}

Although not especially commonplace across England, Scotland and Wales, furniture provision schemes for social lettings have been in existence since at least the 1980s. The Furniture Resource Centre Group (2015) estimate that there are around 70,000 furnished tenancies in mainstream social housing today: around two per cent of the total. Most schemes are small in scale, with the notable exception of Your Homes Newcastle's furniture provision service (see below).

Furniture provision schemes tend to take two forms: direct provision of furniture by housing providers, with a service charge for tenants; and referrals to furniture re-use schemes, which are sometimes funded by the RSL.

\section{Furniture re-use and the VCS}

Many RSLs refer new tenants to charities and social enterprises that provide second hand and recycled furniture to those in need of support. Furniture projects often also work with starter pack and flooring projects to provide the full range of items that a tenant might need. Starter packs might include crockery, pots and pans, curtains and bedding.

There are benefits to referring tenants to re-use projects. These include those outlined by CRNS (2012):

- Furniture projects often include an element of second hand furniture within the packs, bringing down the cost of packs and helping to reduce or eliminate service charges.

- Using furniture projects helps create jobs and training at a local level.

- Established furniture projects have a history of working with vulnerable and disadvantaged people.

However, funding and capacity are key factors in considering the viability of such projects for providing a service to social housing tenants. In some cases RSLs, local authorities or government bodies have provided funding to re-use charities to finance and develop their services. For instance, in 2002, the Scottish Government allocated $£ 7$ million to Scottish local authorities to promote and fund furniture re-use projects. This was a one-off intervention and a more likely means of funding re-use projects is through some form of service level agreement between RSLs and projects. Projects often also seek to fund their activities through other means, such as selling furniture to the general public, service level agreements with local authorities to divert furniture from landfill and providing other services such as removals, gardening and house clearances. This might also include charging tenants for use of the service, something that Shelter Scotland (2010) found was becoming increasingly prevalent in Scotland.

But in most cases voluntary projects receive limited income and as such their capacity to provide furniture is constrained. Such projects are unlikely to have capacity to meet the overall tenant need for furniture. Relatedly, choice for tenants can be limited as a result of the small scale nature of services and reliance on donations. There may also be concerns about the quality of provision when relying on voluntary, unregulated services. In response to this in Scotland a re-use 'quality standard' has been set-up to act as assurance of the quality of goods and services 
being provided. ${ }^{3}$ In addition, where organisations fund furniture provision schemes through the sale of goods to the general public, Shelter (2010) highlight the possibility that better quality items might be reserved for resale, leading to lower quality goods being used for furniture support.

One example of a successful partnership between an RSL and a social enterprise is that of Grangemouth Enterprises Limited (GEL) with Falkirk Council. GEL has three premises including a shop that sells used furniture and computer equipment to the general public. The income from sales is used to provide training and employment opportunities and to provide household goods at low or no cost to people who are in need.

In 2008 Falkirk Council, GEL, and another local furniture re-use organisation, Falkirk Homeless Project, began to work in partnership as 'Quickstart'. This partnership has allowed Falkirk Council to develop a furniture provision service for people who are moving out of homelessness while also linking into other community benefits such as training and volunteering. In a pilot period of six months between January and July 2009 the scheme diverted 41.55 tonnes from landfill and helped 155 homeless people. $^{4}$

\section{In-house schemes}

In addition to supporting tenants through referrals to furniture re-use services, a number of RSLs across England, Scotland and Wales also directly offer furnished tenancies.

The costs for these services are met by the tenant, who pays a service charge for the rental of furniture. This service charge is covered by housing benefit where the tenant is eligible. The ability to charge for furniture provision has been interpreted differently by different RSLs and local authorities in the past, but it is explicitly referred to as a legitimate charge in the latest Universal Credit guidance. ${ }^{5}$ Charges for such a service vary. For instance, Berneslai Homes in Barnsley offers packages ranging from $£ 10.51$ for a basic package in a one bedroom property to $£ 31.65$ for a full package in a three-bedroom house.

While many of these schemes are offered on only a small number of tenancies, there are a small number of examples of larger scale provision, including Glasgow's furnished tenancy service and Your Homes Newcastle's (YHN) furniture provision service, the Newcastle Furniture Service (NFS). NFS operates the largest and longest-running housing provision scheme in England, providing furniture to around 11,000 properties across 14 housing providers including 6,000 Your Homes Newcastle properties (around 20 per cent of YHN stock). NFS employs around 100 staff, operate from a 55,000 sq. ft. warehouse and have a fleet of nine vehicles. Although part of the Your Homes Newcastle ALMO, NFS operates as a business, separate from the rest of the organisation.

The furniture provision service provides choice to tenants by offering a range of options from very basic starter packs to fully furnished tenancies (including white goods). YHN charge from around $£ 9 /$ week for a pack that includes three white goods items up to $£ 40 /$ week for a fully-furnished three bed house. Key points about the service are as follows:

\footnotetext{
${ }^{3}$ http://www.revolvereuse.com/what-revolve

4 Case study material taken from Shelter (2010) Furniture for the homeless: A house without furniture is not a home. Shelter Scotland.

${ }^{5}$ https://www.gov.uk/government/publications/universal-credit-and-rented-housing
} 
- $\quad$ all furniture contracts are taken out at the point of commencing a tenancy: NFS find that housing benefit officers do not take a favourable view on service charges being added on at a later date

- the service includes all repairs and replacements where necessary

- $\quad$ all goods are renewed every four to five years

- $\quad$ used furniture is allocated for another YHN scheme that provides cheap goods to social fund recipients.

- if a tenant moves house with the same landlord or to a landlord that is also part of the scheme they can take the furniture with them

- the furniture service operates a recharge scheme to tenants for lost, stolen or damaged goods. Although a five per cent cost is built into their business planning, in practice it has never been that high

- $\quad$ any surpluses are used by each member housing association to fund additional support services for tenants.

At present $\mathrm{YHN}$ do not have any robust evidence on the impact of the scheme: this is something they are currently working to improve. However, they feel that it does improve sustainability of tenancies, as well as making properties more attractive in the first place to prospective tenants.

\subsection{Summary}

This section presented findings from a review of evidence and practice across England, Scotland and Wales. In terms of the existing literature, although the evidence is limited, it does seem fairly clear that furniture provision can have an impact on the sustainability of tenancies for many new tenants. This support is potentially particularly important for those who have not previously held a tenancy, although there is a range of different circumstances that might lead to the need for support with acquiring furniture.

An initial review of existing practice in England, Scotland and Wales suggests that existing in-house provision is limited to a relatively small number of RSLs. More commonly, new tenants are referred to charitable organisations with limited capacity to provide support. However, organisations such as Your Homes Newcastle show that a comprehensive in-house service can be delivered, and also provide a source of income to the landlord. The legality of funding furniture provision through housing benefit appears to be relatively clear: rather a central concern would appear to revolve around affordability for those moving off housing benefit or those who are ineligible for housing benefit in the first place. 


\section{Stakeholder perceptions of the value of furniture provision}

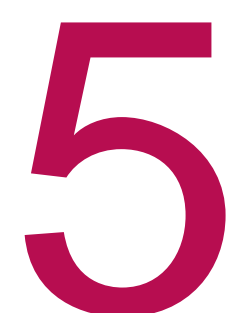

\subsection{Introduction}

This section highlights key findings from stakeholder interviews. It covers stakeholder perceptions of the impact of furniture on tenancy sustainment, which groups are more at risk of facing difficulties furnishing their home, perceptions of existing support services and the perceived value of an NIHE-led service.

\subsection{Impact of inadequate furniture provision tenancy sustainment}

There was consensus among interviewees that inadequate furniture provision has a negative impact on the sustainability of new tenancies. All stakeholders agreed on this. In short, tenants who moved into properties which were deficient in terms of furniture provision were more likely to encounter difficulties sustaining their tenancies.

I would be strong on the argument that the evidence l've seen is that people coming through the homeless route getting their tenancy... their set up is much harder to sustain and it's more of a struggle without a basic starter pack of furniture. Or maybe it's white goods and a kettle and those things and a bed, and for some people what's important to them when they set up.

\subsection{Essential furniture items}

The Research Brief generated by NIHE states that the focus of the research is to assess the impact of furniture provision on new tenancy sustainability. However echoing findings in Section 4 - a key message to emerge from the stakeholder interviews was that the 'problem' (i.e. an inadequately furnished home) was not confined to furniture - tenants who did not have white goods, such as a cooker, washing machine, fridge and television, and home 'start-up' essentials, such as a kettle, crockery and curtains, were also more likely to encounter difficulties. This point is acknowledged by the respondent above and the respondent below:

White goods, it's everything. There's more to a house than furniture and white goods, there's pots and pans, dishes, everything. The very basics like a cooker and a fridge, absolutely fundamental, a kettle, a few pots.

Thus, for the remainder of this section 'furniture' is used to cover all essential household items needed when setting-up a new tenancy. 


\subsection{Existing understanding of the problem}

The furniture provision pilot undertaken by NIHE in its South region generated valuable data on the need for furniture provision for new tenants. Specifically, it found that nearly half of all new tenants in the pilot did not have access to adequate furniture.

I think it was about half of them. It was big. My staff would have told you that was the biggest issue for incoming tenants, furnishing a home.

Yes, when we were doing our pilot $50 \%$ of the people we signed up didn't have access to furniture.

Yet there was a consensus amongst interviewees from NIHE that data were not in place to provide a robust assessment of the need for furniture provision for new tenancies across the organisation as a whole. As one officer noted, while inadequate furniture provision was undoubtedly an important issue, it was impossible to glean an accurate insight into its relative prevalence and magnitude.

It is a big issue, [but] we don't keep any statistics any more.

Collecting data on why tenancies failed would help to address this issue, one respondent felt:

We're starting to collect data. It's terrible to think that we never knew why people were terminating their tenancies, that was something that came out of our original pilot, we need to be looking at that.

\subsection{Furniture provision as a solution to tenancy failure}

As noted above, inadequate furniture provision was highlighted by interviewees as being an important contributor to the failure of tenancies of new tenants. But it was also noted that it was not a quick fix for tenancy failure and implemented in isolation may only have limited impact of tenancy sustainability. As one officer noted:

I think it [furniture provision] is just part of the problem. I don't think it's the whole [solution]. It's going to help, the start of a new tenancy now, change of tenancy, part of systems thinking we're thinking of the quality of the product you give somebody. Because of our supply and demand most of the tenants that come to us have vulnerabilities and issues so basically we're saying if you get a good quality product that gives you one less thing to deal with when you've got all these other issues going on. So we are now looking at putting wooden floors down and painting properties and we can do that without going any further down the road of any projects, but that's just a part of it, it ties into giving somebody a good start.

While a number of factors were identified as contributing to tenancy failure, not least that many of the households housed by NIHE have multiple problems or "vulnerabilities" (see above), a number of respondents highlighted the lack of tenancy readiness of many new tenants as being an important factor. Put simply, many new tenants that NIHE house are ill-equipped and ill-prepared to hold down a tenancy.

A lot of people who applied to become a tenant didn't understand the impact of having a home. So it wasn't just the furniture. It was do you really understand 
what it is to have a home? It's just I'm on the waiting list but no thought to what it means to have a home.

III-prepared is a good description [of many new NIHE tenants]. So a lot of what we've been trying to do in the redesign is to prepare people, that you should start to consider how you save or prepare yourself to have that house. It's as people who don't really understand how it works and maybe are on social benefits maybe believe that when you get a home all of these things are provided and they're not.

I think probably people's understanding of what a tenancy means: the responsibilities that go with it [is a contributor to tenancy failure for ] a lot of people. We're now looking at deferring people so in the past you just allocated somebody a house and that was it, they got it. We're now looking to see if people are tenancy ready, so you might have some young people that come on that have left the family home and have no idea about budgeting, so money management and all of that comes into it and the full range of support.

There was a consensus amongst interviewees that ensuring that new tenants were prepared for their tenancy, along with ensuring that they had access to furniture, would result in them being more likely to sustain their tenancies. However, there was also a view that for those tenants whose lives were particular precarious and complex, even this support would not insulate them against tenancy failure.

There have been some that fell through and terminated and left cos they couldn't sustain their tenancies no matter how much support the officer tried to give, that could be for various reasons, not solely furniture but if you can't furnish and decorate your home and afford it and understand what it means to have a house it will not sustain.

\subsection{How and why is 'furniture' important?}

The relationship between furniture provision and tenancy sustainability was explored with interviewees, with particular attention focusing on how and why inadequate furniture provision impacted on tenant sustainability. It was argued that it contributed to tenancy failure by:

- Undermining the comfort and residential experience of tenants. Clearly, it is very difficult to live in a property when it is devoid of essential furnishing, goods and items such as a bed, sofa, cooker, kettle or even lighting.

You have situations where tenancies have gone south where there's maybe half a dozen young ones sitting in there drinking and there's nothing in there apart from a mattress on the floor and a sofa and a busted TV and the rest of the house there's not even a light bulb in it.

- Having an adverse psychological impact on tenants. A number of interviewees highlighted how living in 'bare' properties had an adverse effect on the psychological state of new tenants.

I can think of countless examples of when... l've gone out to places and it's been as bare as can be and that tenancy has been relinquished very shortly after. We're looking at a couple of cases at the minute where people have lasted only about three days.

One officer felt that there was another dimension to the psychological impact of inadequate furniture provision - tenants felt powerless to respond to their situation 
because they did not have the financial wherewithal (both in the short and long term) to purchase the furniture they needed. As a consequence, the tenancies of these tenants were (understandably) much more likely to fail.

I think the money thing is there cos part of the struggle and decision making process is how am I ever going to change this situation? I'm never going to be able to save any money to be able to go and buy a bed or a sofa or a TV or a fridge. So I think that psychological thing is how do I do this? If you don't have a kettle or a cooker, you might be able to heat your house but if you can't make a cup of tea or make beans on toast where do you go? So it's that psychological thing of future planning and people then make short-term decisions. They're not thinking about their future in that way. They just make very short-term, often poor decisions cos they can't envision how [things will improve].

In many cases we know we're giving them four bare walls and we know their situation is that they're coming with no means, no savings to be able to buy the cooker or this sort of thing.

- Causing new tenants to take on (additional) debt. As alluded to in the quotes above, the financial circumstances of many new tenants were precarious, with most not having savings. Despite their perilous financial circumstances, it was reported that some tenants did purchase furnishings, encountering financial difficulties as a result.

I think debt and affordability is there [as contributor to tenancy failure] cos I think if you're prioritising your rent and food it's hard to envision how you're going to cope.

- $\quad$ Lessening the likelihood that the property will become a 'home' for tenants. A number of studies including Hickman et al (2011) have highlighted that tenants who view their residence as 'home' and not merely 'house' or 'flat' are more likely to exhibit greater levels of ownership and to be committed to it. This commitment may take a number of forms including increased investment in the property and/ or greater determination to ensuring that the tenancy does not fail. Inadequate furniture provision is likely to undermine this commitment and the chances that they will view it as 'home'.

And those are the ones where you want to get in and do some sustainment work and harm reduction and moderating the behaviour of the tenant or whatever to have that option, to bring stuff in to give them a sense of ownership.

\subsection{At risk groups}

Respondents reported that 'furniture' was more likely to be an issue for the following groups, whose membership overlapped: single people; households who had never had a social housing tenancy; younger households; and homeless households:

It's a particular issue around single people. They're less likely to get [a] community care [grant].

Interviewer [I]: Are some people more likely to be affected by the issue? [inadequate furniture provision]

Respondent [R]: Young people.

I: $\quad$ So it's their first, straight from home...

$R$ : Yeah or people who have been transient homeless.

l: $\quad$ So just not used to holding down... 
R: No would probably have been in, haven't had anything, sleeping bag, where they don't have that ability or support to keep in anywhere and it goes round in a circle.

However, there was a consensus amongst respondents that the problem of inadequate furniture provision was not confined to these groups and that it could be an issue for any population group, as often the problem emerged because of an unforeseen life event such as a relationship breakdown or domestic violence.

I think it could be anyone [who could be affected by the problem of inadequate furniture provision]. We're trying to do some profiling on our estates as well, so if you're a patch manager you'll know the income profile of all your tenants, cos there is an argument that you have tenants who maybe get quite a good income from benefits, so if you're getting disability benefits and the full range you could get maybe £500/week on benefits, someone working could be worse off than someone sitting on those benefits, so we're trying to get some profiling and better understanding of our tenants and their needs, cos you have to be realistic. It's individual needs: not everybody's the same.

Yeah, it's other groups so we've had people coming in, marriage break ups, so you've had one house with one tenancy, women fleeing domestic violence, we've had abuse cases coming to light, there's been every scenario you can think of, we've had a 78 year old woman, victim of domestic violence all her life arrived with nothing. So definitely not just the younger end.

\subsection{Furniture as an issue for longer-term tenants}

The focus of this study is on the need for furniture provision for new tenants. However, a number of interviewees noted that longer-term tenants could also experience 'furniture' difficulties and could be housed in properties that were inadequately furnished.

I remember going to visit this lady, we went upstairs, I can't remember why she insisted we went upstairs, but the stairs were just threadbare and your feet stuck to them and we went up to her bedroom and it consisted of a mattress with a duvet with no duvet cover and a pillow and that was it, and that was a long-term tenant with mental health issues. There will always be other issues going on.

I would have thought so. Just cos you've got a tenancy doesn't mean necessarily that your prospects of having furniture and stuff would increase over the years.

I think it should be on the table for not just new tenancies, that's from having to deal with a lot of, cos doing the community safety ASB stuff I've dealt with a lot more vulnerable and impressionable young tenants who have had some unsavoury elements foist themselves on them and ended up the housing being a party house and they have to sustain their tenancy to bring some of those goods in to give that tenant more of a feeling of pride in their house. So I think you wouldn't want to just look at new tenancies, but to have an option and a resource for existing tenancies would definitely be of value.

\subsection{Capacity of existing furniture providers}

A number of interviewees highlighted the key role played by those charities providing furniture to new NIHE tenants, such as St Vincent de Paul and Storehouse. There was a consensus that they provided an excellent service. 
That's where we're using our third parties, which is difficult cos you might not be able to get it there and then, St Vincent de Paul have been brilliant, there's a couple of charities in the town that we're using but then that relies on every office to build up their links with those

However, it was also noted that their capacity was limited and they could not cope with the level of demand generated by NIHE tenants.

We do recognise that the charities and providers of furniture or white goods cannot fully furnish a home but if they can provide an extra couple of beds or a settee that would make her life so much easier. We definitely could, with the assistance of others, make her life and her children's lives easier.

Yes St Vincent de Paul did contact us and say there's too many referrals, they were happy initially, housing executive are standing over this, we will take on board their referrals, but it got to the stage where they couldn't cope with the demand.

When we meet with Storehouse and these organisations, they're voluntary, they've a strong ethos of community base or faith based which is fine but they're quite honest with us to say we can probably do 10 or 12 cases. But if we scale that up and we're looking at 40, 50 referrals a week they just cannot cope. So we'd set them up to fail, as well.

We're aware that when we talk to some of those agencies, their capacity to respond isn't at the scale that we need.

\subsection{Perspectives on NIHE furniture provision}

Given concerns about the ability of furniture provision charities to meet the demands of NIHE tenants, interviewees were asked whether they felt it was appropriate for the Executive to provide furniture directly itself. There was a consensus that it was and there was frustration that the organisation was reliant on charities to meet demand.

I don't understand why we [NIHE] can't do it [furnish properties]. We have officers who know that we have furniture gifted to us by people who leave, lots of furniture, crockery, dishes. We have a person who moved to $x x$ in one of our sheltered complexes. And she's quite a big house. And her daughter was dealing with our officer about moving her goods and they took everything they wanted and left the rest and said you can have it, we got her to sign it over to us, we did keep some of the furniture and gift it to others but we brought stuff into our office and we're going to hold a charity event in October and raffle it and give it to the organisations, hospice or the charities, cos there's goods that were bought for her as presents in their boxes that she doesn't have room for and the family went 'we don't need them'. If we were able to we'd keep them in a store and divvy those out.

Our current model relies on supply, you are relying on another party, if that's the way we have to go that's fine but you get better control and you can be more realistic with people if you're controlling it yourself. Offering to help somebody with St Vincent de Paul or drop in ministries, you can only take it so far and you're relying on somebody else, we do it with the food banks and everything, things like that we're looking to see can we do something ourselves too. It's difficult, but there's a place for these charities too. The housing executive had never thought of furnished tenancies across the board, I think it was always going to be targeted. 
I think as a housing executive and significant social housing landlord, 88,000 properties, potentially a significant part of the community, the question I would have is do we need to rely on social enterprises or do we create a framework in which we play a role and work with social enterprise to work with them where they operate, so there is a social enterprise strategy that we're working on as well. We need to work with social enterprise and support this.

An often-cited concern of social housing landlords when contemplating providing furniture to tenants, and a deterrent to this happening, is that theft will be an issue with the consequent cost of replacing stolen furniture making any scheme unworkable. There was a belief that this was a view held by many officers within NIHE.

When you hear talk [about the possibility of NIHE providing furniture to its new tenants] around an organisation, that is the one message you're hearing from people.

Interviewees were asked their views on the validity of this argument. There was a consensus that the concerns about the loss of goods were not grounded and theft was unlikely to be a major issue if NIHE were to introduce a furniture provision programme. And one respondent cited experience of temporary accommodation projects that supports this argument.

But a lot of these people are in temporary accommodation which is furnished and they're not stealing the stuff out of there.

It is important to make one final point about any provision of furniture by NIHE - there was a view that not all new tenants wanted furnished homes and, even if they did, it was important that the furniture provision they received was tailored to their needs and bespoke.

I think the bottom line is we need to ask our customers do you want a furnished home or not? Cos not everybody wants that. This is not about the housing executive becoming a landlord that has furnished dwellings so they will cost more, cos you will have to build that in. It should be about what does the customer want.

\subsection{Conclusion}

This section built on evidence generated through the data analysis and evidence review. It found that there was a consensus among interviewees that inadequate furniture provision has a negative impact on the sustainability of new tenancies. Importantly, stakeholders felt that it was important to interpret 'furniture' in a broad sense so that it also encompasses white goods and other essential home 'start-up' items. Inadequate furniture provision was identified as being more likely to be more of an issue for certain groups, but all tenants can be affected, and inadequate furniture provision is also an issue for longer-term tenants not only new tenants. The capacity of charity furniture providers to address this need is limited and there was a consensus that NIHE could (and should) provide furniture to its tenants. 


\section{Tenant perceptions on the need for furniture provision}

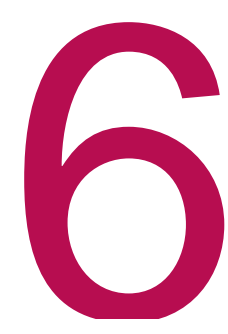

\subsection{Introduction}

This section explores the perceptions of prospective, existing and former tenants in relation to the following:

- importance of furniture in a new home

- what consists of 'essential' furniture in a home

- $\quad$ experiences of furnishing a home

- $\quad$ experiences of existing support services

- $\quad$ the value and preferred nature of a potential NIHE furniture provision service.

The overarching finding is that tenants in a range of different circumstances would value the option of NIHE-provided furniture. Many tenants experienced difficulties in furnishing their homes and most would be willing to pay an additional service charge for the service, especially if this was covered by housing benefit. Confirming stakeholder perspectives, white goods were seen as an essential part of any furniture 'package', but many respondents also said that flooring and curtains were important. There were, however, some questions and concerns about how the service might work in practice: for instance the degree of choice over the furniture they receive; clarity regarding ownership of the furniture; and worries about costs if a tenant moves off housing benefit.

\subsection{The importance of furniture in a new home}

Respondents were unanimous in emphasising the critical importance of furniture to being able to live in a home. This operated on several levels. Practically it was essential that tenants had a minimum level of furniture in order to carry out essential activities such as cooking, washing clothes, sitting down and sleeping. But, echoing Sections 4 and 5 , tenants also referred to the psychological benefits of living in a home that was fully-furnished and decorated against one that was not. Respondents asked how long it took them to feel 'at home' in their current or last tenancy and many talked about this as being directly linked to the time it took to fully furnish and decorate their home. 
When you come in somewhere, you just can't sit on the floor, can you?... especially if you've got problems... it gets to the point, some of the places l've stayed, you may as well be sleeping rough... (existing tenant, 30-59, single)

I'm not completely settled now. It's not done the way I want it to be if you know what I mean. Feels like the place isn't completely decorated yet, feels empty. If there was more furniture in the place... see if you walked into my room, it feels like a skeleton. I need new floors, I've a back room that's missing a bed and tables for the living room, stuff to make it look actually like a home... (existing tenant, 18-29, single)

A number of respondents indicated that they went without essential items both initially (within the first few months) and longer-term. One respondent reported storing food in sinks filled with water where there was no fridge and three others reported eating 'fast food' in the absence of cooking facilities.

Respondents were also asked to outline what they saw as essential items for moving into a new home. The most common responses were: a sofa, a fridge-freezer, a washing machine, a cooker and beds for all residents. Some, but not all respondents, also referred to televisions, microwaves and tumble-driers (for those with children) as essentials. A number of tenants had also moved into homes that required new flooring and curtains/blinds. Having experienced living without these items they had also come to view these as essential to have in place from the start of the tenancy:

Getting everything sorted, all the furniture, the blinds, some houses have no flooring, and flooring takes a big chunk of money. In my last tenancy my stairs had no carpet, for ages, it was tiles downstairs, but the stairs and bedrooms had floorboards, and I couldn't afford carpet. So the whole time I had no carpet... The place looks bare, looks empty, no homely feel (prospective tenant, 18-29, homeless (with partner))

This was common across people in different situations: carpets and curtains/blinds tend not to be transportable from a previous home.

Prospective and existing tenants did not feel concerned about being able to acquire smaller items such as crockery, cutlery and a kettle. Even those on very low incomes - for instance one respondent in receipt of £95 JSA per fortnight - felt that they could acquire these items without too much difficulty. However, this should be balanced with the fact that some prospective tenants did not have a good understanding of the cost of different furniture items and as such had a potentially over-optimistic view on their likely ability to acquire different items. 


\section{Case Study: Joey, East Belfast}

Joey is 51 and claims ESA support allowance. Joey had been homeless for a while and had been 'sofa surfing' before securing a place in a hostel. With help from key workers at the hostel Joey secured a flat.

Joey struggles with completing forms and received support from his key worker in the hostel to begin searching for accommodation.

"Some forms I can, some I don't understand, the questions they ask, I don't understand the phrases."

With guidance from his key workers Joey set the process in motion and secured a property reasonably quickly.

"They [key workers] got me to go and visit the Housing Executive to go and see how many points I had, so once I got to know what points I had they [key workers] started chasing it up to get me a tenancy, they couldn't get one where I wanted so I had to change my area, so they changed my area to $X$ so I got one within a month."

Joey was worried that he may not be able to furnish his property and thought he would struggle to furnish it from his benefit payments. He managed to secure a community care grant of $£ 1400$. He was determined to make his flat a home and bought everything he needed to help him to manage.

He bought a "Washing machine, fridge, suite, telly, bed, drawers and then all the essentials, microwave, kettle, toaster, pots, pans, plates, cutlery and all the bits and pieces."

Joey values the help he received and spoke positively about the community care grant that enabled him to buy the furniture of his choice.

"It's better to have your community care grant, people want to do their flats in their own way, their own furniture and their own taste. The kind of furniture even landlords put into their houses isn't suitable."

Joey was proud of his flat and feels it is cosy and secure something that he values. He was pleased he had furniture as he felt it made a big difference to him. It helped to turn just a flat into a home

"Being able to have furniture, your home's your home, you don't have to go anywhere else, sitting there without a bed in the house and a chair and a wee portable TV, it's no life at all"

Joey thought without furniture he would have given up the flat and returned to sofa surfing.

\subsection{Experiences of furnishing a new home}

Respondents outlined a range of challenges that they faced when furnishing their homes. In some cases it had taken new tenants up to two years to completely furnish their homes and to 'feel at home'. In general terms being unfurnished made it more difficult to settle in the tenancy, and furnishing was often seen as the most challenging aspect of moving into a new tenancy

For me, my main challenge was finding furniture... pretty much had just started my job, and I was entitled to any help from the brew, and had to wait two months for my first paycheque, and on top of that, try to pay my first month's rent...and get furniture and everything I needed for the flat, pretty tricky... (existing tenant, 18-29, single) 
Where tenants needed to acquire furniture, they had acquired them from a range of sources, including buying new furniture, buying second-hand from internet trading sites and charitable organisations, gifts from family and friends and - in some cases provision from VCS organisations.

Respondents frequently talked of 'going without' in order to pay to furnish their home, in particular heating or food, but also - as noted above - clothes for children. Respondents had taken different strategies to paying for furniture. New furniture was often paid for through a loan taken out with the company they bought the items from. This was expensive. One respondent, who was a full-time carer for her partner and two children, was paying £95 per month over 18 months to repay a loan taken out to buy a new sofa: "It causes difficulties. I've been able to pay every month but we do have trouble. We're often cutting back on other things coming up to the month - cutting back on shopping, things for the boys you know, things like that" (current tenant, 30, young family).

Another respondent talked about the debts they had accrued decorating their home, and - echoing other tenants - talked in particular about the costs of installing new flooring.

It wasn't decorated, there was no flooring down, I had to put all that down myself... All in it would have cost about $£ 3000$ although, that's everything, getting a decorator out to do it and stuff like that. I'm still paying it off even though I don't still live there, paying off the credit card... I think it's £89.54 per month. The housing executive leave you the whole house, well the downstairs is kitted out with these stupid mustard coloured clay tiles and they think that is an adequate floor, they're terrible. I know some housing association houses, once you move into a new property which a previous tenant has been in, they're carpeted from top to bottom, if you want to change it it's down to your personal choices, if the carpet stays and it gets damaged you pay for it obviously, that's fair enough, but if you move in and it's looked after you don't mind that (former tenant, 27, single)

A third respondent had recently become unemployed as a result of a workplace injury that left them unable to work. He was waiting for his ESA payments to start and was struggling to keep up with debts caused in part by buying furniture.

R:Yes to date l'd say it's probably cost me between 8 and 10 grand just to set up a new home cos of the state of all my stuff in the previous property. I haven't paid all that straight away, l've been building stuff up over the year, buying bits and pieces.

I: Have you been saving up or buying stuff that you pay back over time?

$R$ : Just trying to get my stuff on finance, most of my stuff I got on finance, my suite and stuff like that, the bedroom furniture, new bed, got it all on finance.

I: Are you still managing that cos you said you've not got money coming in, is that causing problems?

R:l've had to get onto them and ask them can the cut the payments down for a wee while which to be fair the finance company, I had like an insurance policy with the finance company and they're helping me as long as I can pay a wee bit towards it but I don't know what I'm getting yet so I don't know how much I have to pay back. My overhead is going out every month on that stuff plus the likes of insurance for my car and the car payment never mind having to pay overheads for a previous property.

I: Do you mind me asking how much you've been paying back on finance? 
R: On finance I probably pay out £5 or 600/month. That's everything, that would be for my car, insurance, the suite, the bedroom furniture, phone bill, stuff like that. (current tenant, single, 28)

Reflecting on their experiences another former tenant talked about their regret, having got into considerable debt buying new furniture:

The only thing I would say is if it would help anybody would be not to go and buy new furniture because you'll end up being in a hell of a lot of debt and for the short time you're going to end up staying in the house anyway, unless you're a long-term tenant, I wouldn't advise it. You could go to any furniture charity shop and pick up things and they're always good quality otherwise they wouldn't take them in, that's something that maybe I should have looked at but at that stage it was my first house and I thought to hell with it, I was planning on staying in the house but it was more the area I was in that I didn't like, the atmosphere and the area (former tenant, 27, single)

It is also worth noting that replacing damaged or expired goods can also be problematic: as one respondent outlined, often these items are simply not replaced when limited finances are allocated to essentials, such as food, electricity and gas.

The kettle broke... my hoover broke, and I still haven't got one. I can't just afford it, because once you pay your gas and electric and all, buying food... (existing tenant, 18-29, single) 


\section{Box 1: Katie, 22, existing tenant (Newry)}

Katie has been an NIHE tenant for 7 months. She lives alone. She was recently made unemployed and had not yet applied for benefits or found new employment. Prior to moving into her current property, the participant was homeless, and living in temporary accommodation.

"'II was pretty much homeless for near five years...mainly different temporary accommodations. I was mainly on benefits... then I was in self-contained flat owned by a hostel. I saw my flat on a letting website and applied. I was just looking for anything within the price range I could afford at the time..."

The main challenge for Katie in setting up home was securing furniture on limited finances. She felt these issues were particularly marked for young people who may not have the necessary support to navigate this difficult phase of setting up home.

"I think probably [the main challenge for young people] would be finding trying to find someone to help you move...if you're like me, l'd no-one to help but then XXXX and XXX [CHNI youth workers] helped..."

As for essential start-up items:

"pretty much everything really...you're gonna need one wee seat or something to sit on...something to sleep in like a bed...your kitchen stuff...a fridge and something to cook in...there the main things really..."

Katie had received a starter pack from a homelessness charity, but she had to cope without other furniture. The participant described how she relied on the support of a number of charitable organisations:

"I got the wee starting up thing, which was absolutely amazing. It got me towels, microwave, kettle, toaster, it was absolutely brilliant. I moved into the flat and I didn't have sofas, I was sleeping on a blow-up bed. The starter pack I got on the day I moved in, but the rest I pretty much had to deal without. I was sleeping on a blow-up bed, and using it as a seat as well... the hostel I was in, the receptionist had mentioned a charity that would be able help get stuff, I think it was called Helping Hands. I got given a chest of drawers, wardrobe, a bed, and sofas. I had a mini oven. That was the only thing I had when I moved in to the flat and then through the starter pack, I got the kettle, toaster, microwave. Helping Hands got me a fridge, I owned a washing machine..."

\subsection{Existing support and its value}

Respondents had often received some support to furnish their homes, most commonly from family or friends. Many tenants had also received some formal furniture provision or support with acquiring furniture, in particular those that were living in hostels or supported accommodation, but also other tenants who had received community care grants, crisis loans or 'social fund' assistance to help with costs of furnishing the home. For those moving into a tenancy from a hostel or supported accommodation, the support they received was vital in securing and sustaining a tenancy. Furniture provision/support was one element among a wider support package, but was nonetheless important.

For those that were able to access them, community care grants were of great help to those starting out with no furniture. Respondents spoke positively about their access to this and how it helped them to buy the basics: cooker, bed, fridge sofa and so on. Additionally respondents valued the funding to undertake decorating and buy carpets and other furnishings if they had money to spare. Some respondents did, however, mention that delays in receiving the grant meant that there was an initial period where their new home was either considered uninhabitable or that they were forced to 'make do' without furnishing for 4-6 weeks.

Respondents referred to a number of other potential sources of support, including: 
- 'Helping Hands' (Facebook-based community)

- $\quad$ Floating Support MACS (Leaving and aftercare service)

- Simon Community CBS (homelessness organisation)

- $\quad \mathrm{CHNI}$ starter packs

- Bootle Trust

- $\quad$ St Vincent De Paul

- Gumtree

Existing links to charities and other supporting organisations such as St Vincent de Paul were vital in helping respondents secure furnishings especially those who were unable to access a community care grant. One tenant outlined the difference that furniture had made to them:

Having had them, if I hadn't I would have struggled till the next pay day... there's times I skip meals just to pay rent and stuff so knowing that I had cooker, sofa, fridge and stuff like that... It does make a heck of a difference.

\subsection{Perception of the value of an NIHE service}

Prospective tenants thought that some form of support with furnishing their home would be helpful, especially those that were currently living in hostel or sheltered accommodation. The provision of actual furniture was seen as more useful than a grant to the equivalent value because it meant that the property would be a 'home' right from moving in:

It would be a great help for people moving into a flat. People moving in with nothing there, it brings people down, even if they have to wait for a community care grant, if something's sitting there [it would make a difference] until I get something better so it would be a great help (tenant, Belfast)

Another respondent felt also that direct provision of furniture would be of greater value than a grant for people entering their first tenancy, who might not be experienced in acquiring furniture, might not be sure what furniture they will need, and might also be inexperienced in managing their finances:

[With the community care grant] I bought the fridge, but it broke, I got the money back, but I spent it, I wasted the money. You'll find with young people you give them all this money and they waste it. And I can't save up money, and I'm on benefits, so I never got the fridge. (Prospective tenant, 18-29, single)

It is also important to note that respondents in a wide range of circumstances had experienced difficulties with furnishing their homes, not only those eligible for community care grants. Several respondents, for example, reported having unsuccessfully applied for a grant in the past.

...getting a Community Care grant was quite difficult. They gave me fifty quid or something like that for blinds...and I appealed, then they gave me another ten quid for something else... financially it was difficult... (prospective tenant, 18-29, single)

Respondents were especially positive about the scheme if it could be covered by housing benefit. Nonetheless, most existing and prospective tenants felt that they would be willing to pay additional rent from their own money to live in a furnished tenancy, although this would depend on how much and on the furniture on offer. 
That would have been good, if l'd been offered that at the start that would have been something I would have been interested in, even it was an extra $£ 10$ or $15 /$ week in your rent, I would have paid that cos I would have been happy cos I wouldn't have to go and buy it all. (former tenant, single, 27)

Some others did suggest that they would not likely take on the scheme if it was not covered by their housing benefit, however, as they were struggling financially already and did not think they could manage an extra cost.

Me personally, probably not, because I can hardly afford things as it is. My sister would buy wee ornaments for the house, but I can't afford to do that...I'm trying to manage my money... so, no... (current tenant, single, 18-29)

On the whole respondents would still be interested even if they did not own the furniture at the end of the tenancy.

Respondents were keen that as a minimum this covered the essential items outlined above: a sofa, fridge/freezer, cooker and beds, as well as flooring and curtains/blinds but felt that they would likely provide smaller items such as kettles, cutlery and crockery themselves.

It would be basic things that would keep me clean, things like that, just basic. You don't need luxury, you just need somewhere to lay your head and that's it. (former tenant, 27, single)

Flooring in particular had evoked strong feelings from some respondents given the expense of installing flooring and a perception that NIHE stripped out existing flooring without regard for its state of repair prior to the start of a new tenancy.

\section{Concerns}

Despite overriding positivity towards a potential furniture support scheme, respondents did have a number of further questions and concerns about its operation. Respondents were particularly interested in the level of flexibility afforded to tenants, for example, whether items could be 'returned' if the tenant was able to find an alternative:

I need to know a lot more about how it would work. I mean, if I was say renting a bed and my ma said I could have an old one of hers or something. Could I give it back and stop paying for the bed? Would that be possible? If not, I'd feel like I was wasting money (prospective tenant, 33, single)

The same respondent was also concerned about the impact that coming off housing benefit might have and the financial strain an additional charge might bring once he was in paid employment; and a more emotional concern for 'ownership' of furnishings:

It would be ideal if it was covered by housing benefit but what happens when I'm working again? It seems a bit strange renting furniture. It's usually one of the few things you can say you own. l'd be weighing up whether l'd be better picking up bargains here and there. 
The issue of ownership was raised by other respondents who felt that not owning the furniture at the end of the tenancy would then leave them needing to go through the challenges of acquiring furnishings in their next tenancy. This was only seen to be an issue if there was no similar option for a furnished tenancy in future tenancies, however. Another related concern was the length of time that tenants would be paying for rented furniture before it became more expensive than having bought their own. Others also raised questions about responsibility for replacing and/or repairing furnishings.

Another important factor was choice. While some respondents - usually those who had experienced the most challenging situations - felt that a basic furniture pack would be sufficient in itself, others felt that it was important that tenants were given choice over different options. This related to which items they could receive, but also choice over the style of different items.

I wouldn't want to just be given a sort of standard package of things, like 'this is what you need to set up home' cos there are things of mine that are fine and other things that need replacing. So, what happens if I get some stuff and then later something breaks and I need to replace that, can I add that on?

\subsection{Conclusion}

This section outlined the findings from interviews with former, existing and prospective NIHE tenants. There are three key points that can be distilled from these findings.

First, furniture and décor are critical to how tenants feel about their homes. Yet tenants often found it very challenging to furnish and decorate their homes, often spending relatively long periods without items that they saw as essential. For some tenants, this was exacerbated by a perception that NIHE had stripped out useable furnishings and floorings before they moved into a property.

Second, support with furnishing was greatly valued by those that had received it from existing sources. However, for many, in order for their tenancy to be a success, furnishing was one, albeit important, part of a wider support service. Similarly existing support services were not able to provide support to all those in need. This includes state-provided grants such as the Community Care Grant.

Third, a furnishing scheme provided by NIHE would be valued by most respondents. This included those with relatively high-level needs or who were entering a tenancy for a first time as well as those who might be considered as more 'resilient' or selfsufficient. The fact that different groups of tenants would value such a service suggests the potential for a broadly available 'furnished tenancy' offer as provided by some English, Scottish and Welsh housing providers. This will be discussed in more detail in the policy implications, below. 


\section{Conclusions and policy implications}

\subsection{Key findings}

Drawing on a variety of sources, this report has set out the findings of research to assess the need for furniture provision for new NIHE tenants. The key points from this can be summarised as follows:

- It is true to say that some population groups are more at risk than others of needing support with their tenancy, including furniture support. This includes people moving into a new tenancy following a period of homelessness, people entering their first independent tenancy (in particular, care leavers), people leaving prison, those who have had to move as a result of marriage breakdown or other circumstances that meant they were unable to bring their furniture from a previous home. But it is also important to note that all tenants interviewed experience challenges furnishing their homes, not just those who might be classified as more vulnerable or at risk.

- As an extension of the above, tenants in a wide range of situations reported that they would value some form of furniture provision.

- For those in critical need, furniture alone is unlikely to remove risk of tenancy failure: it is important to remember that this needs to be part of a wider package of support.

- It is important that any service includes white goods, and NIHE might also want to review their policy towards flooring and curtains.

- We could develop a crude binary typology of 'furniture need':

1. Those that have no furniture prior to starting their tenancy and no means to provide their own furniture. These tenants were concerned chiefly with having 'the basics' to start them off - fridge, cooker, sofa, bed. They were less concerned with choice.

2. Those that face challenges with furnishing their home, but feel that they would manage to furnish it themselves (over time). This group valued a service and would be willing to pay, but were concerned about choice.

- Tenants would be willing to pay for furniture provision, especially if covered by housing benefit and in many cases even if it was not. There was, however, some concern about what happens if a tenant comes off housing benefit and the risk of increasing the housing benefit 'poverty trap'.

- There are a number of different provision options for NIHE, but these could be distilled into two categories, in line with the 'furniture needs' groups. 
1. A targeted service aimed at providing essential items to those in critical need.

2. A more widely available 'furnished tenancy' offer - as in the PRS - to tenants. This has been successfully implemented by, for example, Your Homes Newcastle in England. It can improve tenancy sustainment but also create an income stream for NIHE. This could even be offered as a service to other housing providers in Northern Ireland.

- A rental arrangement for furniture would also mean replacing furniture periodically and being responsible for repairs. Evidence from elsewhere suggests that the risks for NIHE are relatively low. This approach would also reduce risks for longer-term tenants who face difficulties replacing their own furniture.

- A more general finding for NIHE, which impacts on efforts to improve tenancy sustainment, is that data on tenants are rather patchy and as a result limit the level of analysis that can be carried out to understand the nature of the tenant population or the problems that different tenants face. As noted above, many of the contact numbers for existing tenants were no longer in use, which will likely create practical problems for NIHE when attempting to contact and/or support tenants in difficulty.

\subsection{Policy implications}

As outlined above, the majority of tenants interviewed as part of this study felt that the direct provision of furniture (as opposed to grants) would be very helpful and welcome. Moreover, many may also be willing to pay more in rent/an additional service charge for a furnished property. The literature also provides support for furniture provision, suggesting it has the potential to support tenancy sustainment and in this sense; protect revenue for housing providers and may also yield a range of 'psycho-social' benefits for tenants (see Scoping Report, September 2015). NIHE representatives interviewed as part of this study recognised these potential benefits and would also be supportive of such a move.

However, questions remain about how exactly such a service would be implemented. Key questions included:

- Who should pick up the cost of the furniture provided?

- Would housing benefit cover the additional costs associated with living in a furnished property?

- Who decides what furniture is provided?

- Who would own the furniture at the end of the tenancy?

- Would the tenant be able to take the furniture with them at the end of a tenancy even if they had not finished paying for it?

- Who is responsible for maintenance?

- Could a tenant end the furniture element of the tenancy whilst remaining in the same property?

This section addresses these questions by drawing together existing knowledge about the legalities and policy implications associated with the housing providers supplying furniture to tenants. Here we draw on two key sources: interviews with housing provider staff responsible for implementing one of the UK's largest furnished social housing scheme and DWP guidance on Universal Credit, which provides the framework within which RSLs wishing to offer additional services to tenants (paid for 
through housing benefit) must operate. It is also informed by review of information provided through the websites of housing providers providing furnished tenancies.

\subsection{Existing practice}

It is relatively unusual for housing providers in England, Scotland and Wales to offer furnished tenancies. However, some do and there are estimated to be around 70,000 such tenancies in 'mainstream' social housing today: around two per cent of the total (Furniture Resource Centre Group, 2015). These existing schemes tend to fall into one of two categories: direct provision of furniture paid for by a service charge or through referrals to furniture re-use schemes, sometimes funded by the housing provider but not always.

\section{Referrals to VCS schemes}

As set out in the Scoping Report submitted by the research team in September 2015, many RSLs use referrals to charities and social enterprises that provide second hand and recycled furniture as a way of helping meet tenants needs for low cost furnishings. However, regardless of who covers the costs of accessing such services, there are several key disadvantages to this approach, including a lack of capacity within such organisations to meet the needs of large numbers of households and the fact that tenants will be unable to cover the costs of items acquired through HB. Tenants using such a service may also be unable to source the items they need or may be confronted with a lack of choice, due to charities reliance on donations.

\section{Experience from Your Housing Newcastle and other providers}

One of the largest furniture provision schemes operated by an RSL in the UK is run by Your Homes Newcastle (YHN). The furniture provision arm of the organisation is run as a separate company and provides furnishings to 17 other RSLs. Very similar schemes are also operated by Liverpool Mutual Homes (LMH), ${ }^{6}$ Swansea Council, ${ }^{7}$ Asra Housing Group, ${ }^{8}$ One Vision Housing ${ }^{9}$ and Berneslai Homes ${ }^{10}$ albeit with varying terms and conditions attached. Interviews with staff responsible for the YHN scheme and reviews of the websites of the other providers listed has generated some insights into how furniture provision might be approached in a way which is compatible with government regulations and the housing benefit system.

YHN rent most of their furniture to tenants through furnished tenancies and although they do occasionally sell items to tenants, this is rare. If tenants choose to sign up to the scheme, they are offered a choice of five furniture 'packs' of different sizes and values. Tenants are offered the opportunity to take on a furnished tenancy when they are signing up for a property. This opportunity is not generally available to YHN tenants at a later date, unless there are exceptional circumstances (such as a house fire). This is the case for most of the RSLs we found which offer this service, with the exception of One Vision Housing who will consider applications for furniture support at any time during the tenancy.

If tenants opt for a furnished tenancy, a service charge is added to their rent account, which can be covered by housing benefit if the tenant is in receipt of this. Where the service charge is covered through $\mathrm{HB}$, as is most often the case, then the furniture

\footnotetext{
${ }^{6}{ }^{6}$ https://www.liverpoolmutualhomes.org/your-home/your-rights-and-responsibilities/furnished-tenancies/

7 http://www.swansea.gov.uk/article/5307/Furnished-tenancies

8 http://www.asra.org.uk/property-shop/renting-with-asra/furnished-tenancies/

9 http://ovh.org.uk/wp-content/uploads/2013/01/Furnished-tenancies-leaflet.pdf

${ }^{10}$ http://www.berneslaihomes.co.uk/your-home/furnished-tenancies/
} 
will only ever be rented by the tenant (regardless of the length of time they are renting it for) and will remain in the ownership of the provider. This is due to DWP requirements, outlined below. Yet, in the case of YHN, they do replace the pack every four or five years and cover all replacements and repairs, assuring that tenants are receiving value for money. Similarly, LMH will replace all items that are no longer fit for purpose as a result of general wear and tear.

YHN provide a complete service on behalf of the landlords that subscribe to their service, from delivery to renewal but it is the RSL that determines the cost of the weekly service charge to tenants which vary according the size and content of the pack but must be 'reasonable', as required by the DWP. The RSL then pays YHN on a monthly basis.

According to a senior member of YHN staff, the risk that items of furniture will be sold on, lost or destroyed is low, in their experience. However, an additional five per cent is added on to the costs of the packs (charged to landlords) to cover the cost of replacements in this eventuality. The cost of any lost, stolen of destroyed items would not be covered through HB and would fall to the landlord initially, who would attempt to recoup the amount from the tenant. The respondent also reported that many RSLs also add a small surcharge to the service charge paid by tenants to enable generation of a small surplus to reinvest in other services. This surcharge is generally also covered by HB.

There are, however, concerns among staff at YHN that once Universal Credit is rolled out, some tenants may not keep up rent payments to their landlords, including service charges for furniture. This is a threat to the business model that YHN has employed with success for a number of years.

\section{Regulations: Universal Credit service charge guidance}

Where RSLs provide furniture directly to their tenants, this is generally covered through a service charge covered by HB where the tenant is in receipt of this. Although there has been some ambiguity in the past regarding whether RSLs can charge for the provision of furniture to tenants, the latest Universal Credit guidance is clear that this is a legitimate charge as it would be classified as: "a payment of or towards the costs of or charges for providing services or facilities for use or benefit of person occupying the accommodation" (DWP, 2013). The provision of "basic furniture or essential domestic appliances to tenants in the accommodation they occupy only when being rented" is permitted under Category D of the Universal Credit guidance (DWP, 2013).

Under Universal Credit, any service charges that landlords are permitted to charge to tenants are paid as part of the monthly sum the tenant receives under Universal Credit. It will then be incumbent on the tenant to ensure this money is paid to their landlord. The risk associated with non-payment of the service charge is therefore borne by the landlord, but also by the tenant who, as the UC guidance states, will be in breach of their tenancy agreement if they do not pay the charge(s). The guidance also stipulates that no service charge must result in tenants acquiring an asset. This is why tenants will never be able to own the furniture they are supplied with, as would be the case under a Hire Purchase agreement, for example. 
Summary of insights into key questions:

\begin{tabular}{|c|c|c|}
\hline Questions & Insights & Sources \\
\hline $\begin{array}{l}\text { Who should pick up the } \\
\text { cost of the furniture } \\
\text { provided? }\end{array}$ & $\begin{array}{l}\text { A service charge is generally added to the } \\
\text { rent account and is covered by } \mathrm{HB} \text { (see } \\
\text { below) or the tenant, if they are not in } \\
\text { receipt of } \mathrm{HB} \text {. }\end{array}$ & $\begin{array}{l}\text { Interviews with YHN } \\
\text { staff. Universal } \\
\text { Credit guidance } \\
\text { (DWP, 2013). }\end{array}$ \\
\hline $\begin{array}{l}\text { Who decides what } \\
\text { furniture is provided? }\end{array}$ & $\begin{array}{l}\text { Any items proposed for inclusion in the } \\
\text { packs have to be approved by DWP as } \\
\text { 'essential items'. Energy efficient } \\
\text { appliances and good quality goods are } \\
\text { preferred by YHN. }\end{array}$ & $\begin{array}{l}\text { Interviews with YHN } \\
\text { staff. }\end{array}$ \\
\hline $\begin{array}{l}\text { Who sets the cost of } \\
\text { furniture provision? }\end{array}$ & $\begin{array}{l}\text { In the case of YHN, the RSL determines } \\
\text { the cost of the service charge. The } \\
\text { landlord then pays YHN monthly. RSLs } \\
\text { usually add a surcharge which is usually } \\
\text { covered by HB and enables a small profit } \\
\text { for the RSL. The DWP stipulate that these } \\
\text { charges must be 'reasonable'. }\end{array}$ & $\begin{array}{l}\text { Interviews with YHN } \\
\text { staff. Universal } \\
\text { Credit guidance } \\
\text { (DWP, 2013). }\end{array}$ \\
\hline $\begin{array}{l}\text { Would housing benefit } \\
\text { cover the additional } \\
\text { costs associated with } \\
\text { living in a furnished } \\
\text { property? }\end{array}$ & $\begin{array}{l}\text { Yes, the latest Universal Credit guidance } \\
\text { is clear that this is a legitimate charge. }\end{array}$ & $\begin{array}{l}\text { Universal Credit } \\
\text { guidance (DWP, } \\
\text { 2013) }\end{array}$ \\
\hline $\begin{array}{l}\text { Who would own the } \\
\text { furniture at the end of } \\
\text { the tenancy? }\end{array}$ & $\begin{array}{l}\text { If paid for through } \mathrm{HB} \text {, then the tenant } \\
\text { only ever rents the furniture and it remains } \\
\text { the property of the RSL (or other } \\
\text { provider). Service Charges must not } \\
\text { enable a tenant to acquire an asset. }\end{array}$ & $\begin{array}{l}\text { Interviews with YHN } \\
\text { staff. Universal } \\
\text { Credit guidance } \\
\text { (DWP,2013) }\end{array}$ \\
\hline $\begin{array}{l}\text { Would the tenant be } \\
\text { able to take the furniture } \\
\text { with them at the end of a } \\
\text { tenancy? }\end{array}$ & $\begin{array}{l}\text { In the case of YHN, only if they are } \\
\text { moving to a property either owned by the } \\
\text { same RSL or by another RSL that they } \\
\text { provide a furniture service to. }\end{array}$ & $\begin{array}{l}\text { Interviews with YHN } \\
\text { staff. }\end{array}$ \\
\hline $\begin{array}{l}\text { Who is responsible for } \\
\text { maintenance? }\end{array}$ & $\begin{array}{l}\text { In the case of YHN, the provider (and } \\
\text { owner) of the furniture. }\end{array}$ & $\begin{array}{l}\text { Interviews with YHN } \\
\text { staff. }\end{array}$ \\
\hline $\begin{array}{l}\text { Who pays for loss or } \\
\text { damage? }\end{array}$ & $\begin{array}{l}\text { At YHN, the RSL would generally be } \\
\text { asked to cover the cost of replacing lost, } \\
\text { stolen or destroyed items (depending on } \\
\text { the exact circumstances). It would be up } \\
\text { to the landlord to recoup these costs from } \\
\text { tenants. }\end{array}$ & $\begin{array}{l}\text { Interviews with YHN } \\
\text { staff. }\end{array}$ \\
\hline $\begin{array}{l}\text { Could a tenant end the } \\
\text { furniture element of the } \\
\text { tenancy whilst remaining } \\
\text { in the same property? }\end{array}$ & $\begin{array}{l}\text { At Asra HG, a tenant has to honour the } \\
\text { agreement for a minimum of } 12 \text { months, } \\
\text { after which time they can cancel without } \\
\text { penalty. At Berneslai Homes, the } \\
\text { agreement is in perpetuity. One Vision } \\
\text { operates a discretionary policy on this. Of } \\
\text { the case studies cited, only One Vision } \\
\text { allows tenants to take out a furniture } \\
\text { package during their tenancy. }\end{array}$ & $\begin{array}{l}\text { Asra Housing Group } \\
\text { website. Berneslai } \\
\text { Homes website. One } \\
\text { Vision Housing } \\
\text { website. }\end{array}$ \\
\hline $\begin{array}{l}\text { What proportion of } \\
\text { tenants are likely to take } \\
\text { such a scheme up? }\end{array}$ & $\begin{array}{l}\text { At YHN, just over } 1 / 6 \text { have taken on a } \\
\text { furnished tenancy. It is felt this number } \\
\text { would be higher if the scheme was always } \\
\text { offered at sign-up. }\end{array}$ & $\begin{array}{l}\text { Interviews with YHN } \\
\text { staff. }\end{array}$ \\
\hline
\end{tabular}




\subsection{Policy implications}

Drawing on the above, NIHE may wish to consider:

- The capacity of furniture charities to cope with demand if referring tenants on to them and the potential disadvantages for tenants.

- Whether it would be better to set up their own service for the provision of furniture or to make use of the services of any that already exist in the region. The former will require a lot of development work and ongoing management if a complete service is to be provided.

- $\quad$ The scope of a new service and who it should be available to.

- The impact of charges on tenants who move off housing benefit/Universal Credit as a result of finding paid employment.

- Its approach to risk management where tenants default on payments or lose, steal or destroy furniture supplied through the scheme. Non-payment is considered more likely under Universal Credit.

This report found support for an NIHE-led furniture support service from tenants and stakeholders, reinforced by existing evidence from policy and practice in England Scotland and Wales. Some of the policy implications of this have been outlined, although there remains significant work for NIHE to do in order to scope out the nature of such a service. 


\section{References}

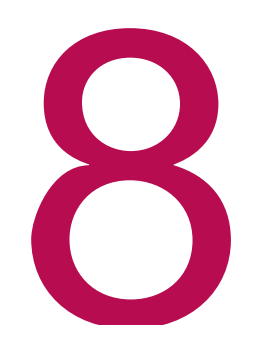

CRNS (2012) Buying packs from furniture projects: A Toolkit for Local Authorities and Registered Social Landlords. Edinburgh, CRNS.

JRF (1997) The viability of furnished tenancies in social housing JRF Housing Research 224, October 1997. http://www.jrf.org.uk/sites/files/jif/h224.pdf

Hickman, P., Walshaw, A., Ferrari, E., Gore, T. and Wilson, I. (2011) "The Houses all Look Posh Now" - Evaluating the Impact of a Housing Improvement Programme: The Case of Portobello and Belle Vue. Sheffield: CRESR, Sheffield Hallam University. Available at: http://www.shu.ac.uk/research/cresr/sites/shu.ac.uk/files/houses-all-look-posh-now.pdf

Homelessness Task Force (2002) Helping Homeless People: An Action Plan for Prevention and Effective Response. Scottish Executive, Edinburgh. http://www.clacksweb.org.uk/document/272.pdf

Pawson, H., Donohoe, T., Munro, M., Netto, G. and Wager, F. (2006) Investigating Tenancy Sustainment in Glasgow. Report to Glasgow Housing Association and Glasgow City Council, April 2006.

Pawson, H. and Monroe, M. (2010) Explaining Tenancy Sustainment Rates in British Social Rented Housing: The Roles of Management, Vulnerability and Choice Urban Studies 47, 1 145-168.

Richards, A. (2007) Yorkshire Housing Group Fresh Start Scheme: Social Return on Investment Analysis. Liverpool John Moore's University, Liverpool.

Rooney, B. (1997) The viability of furnished tenancies in social housing. JRF, York.

Shelter Scotland (2010) Furniture for the homeless: a house without furniture is not a home. Shelter Scotland and Community Recycling Network for Scotland. http://scotland.shelter.org.uk/ data/assets/pdf file/0009/286281/Furniture for the homeles s - FINAL report.pdf

Stewart, A. (2013) Managing a Tenancy: Young people's pathways into and sustaining independent tenancies from homelessness. PhD thesis, Stirling University. https://dspace.stir.ac.uk/bitstream/1893/20409/1/managing a tenancy.pdf

Timmins, V. and Gulliver, K. (2015) Furnishing homes, furnishing lives: an initial discussion of how furnished tenancies support sustainable communities. Furniture Resource Centre

Tsai, J., Mares, A. S. and Rosenheck, R. A. (2012) Housing satisfaction among chronically homeless adults: Identification of its major domains, changes over time, and relation to 
subjective well-being and functional outcomes, Community Mental Health Journal, 48(3), pp. 255-263.

Warnes, A., Crane, M. and Coward, S. (2013) Factors that Influence the Outcomes of Single Homeless People's Rehousing, Housing Studies, 28:5, 782-798. 


\section{Sheffield Hallam University}

Assessment of the need for furniture provision for new NIHE tenants

AMBROSE, Aimee <http://orcid.org/0000-0002-5898-6314>, BATTY, Elaine

<http://orcid.org/0000-0001-7524-3515>, EADSON, William <http://orcid.org/0000-0002-

2158-7205>, HICKMAN, Paul <http://orcid.org/0000-0002-3062-0003> and QUINN,

George

Available from the Sheffield Hallam University Research Archive (SHURA) at:

http://shura.shu.ac.uk/15614/

\section{Copyright and re-use policy}

Please visit http://shura.shu.ac.uk/15614/ and http://shura.shu.ac.uk/information.html for further details about copyright and re-use permissions. 